Faculdade de Ciências Econômicas UFRGS
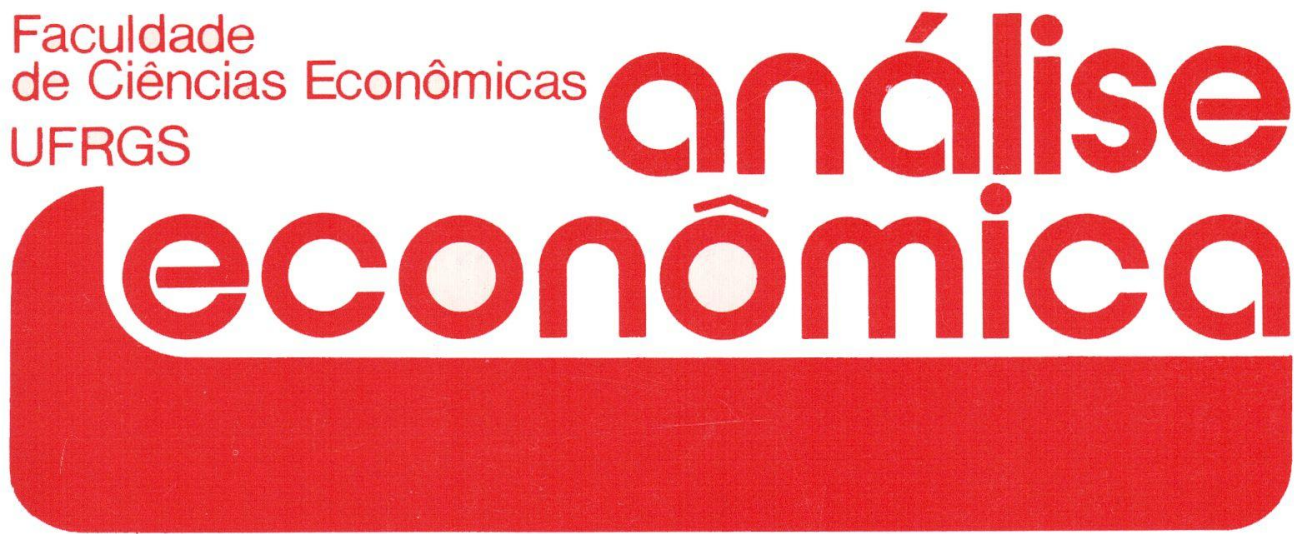

- STATE AND THE LIBERALIZATION OF THE BRAZILIAN ECONOMY

Carlos Alberto Longo

- MOEDA E CRÉDITO NA ECONOMIA BRASILEIRA: UM MODELO COM VETORES DE CORREÇÃO DE ERROS

Rolando M. Guzmán

- baSES PARA UM NOVO MOdELO DE POLítica FISCAL, PARA O BRASIL

Flávio Riani

- POR QUE OS SINOS DOBRAM? CONFLITO TRABALHISTA E SALÁRIOS DO MAGISTÉRIO PÚBLICO DO RIO GRANDE DO SUL, 1974-1991

Carlos Henrique Horn

Roberto Balau Calazans

- A POLÍtica MONETÁRIa E AS TAXAS de JUROS NO PLANO COLLOR

Lauro Lobo Burle

- DIFUSÃo E TRANSFERÊNCIA DA TECNOLOGIA DE PRODUÇÃO DE CIMENTO NO BRASIL

Maria Cristina Pereira de Melo

- SISTEMA FINANCEIRO BRASILEIRO: UMA PROPOSTA dE disCuSSÃo

Luiz Felipe Serpa

- TEORIA ECONÓMICA DO CASAMENTO E DO Divórcio

Giácomo Balbinotto Neto

- RESENHA

VARGAS: O CAPITALISMO EM CONSTRUÇÃO, DE PEDRO C. D. FONSECA

João Rogério Sanson

- LIVROS RECEBIDOS

Claudine Saldanha César
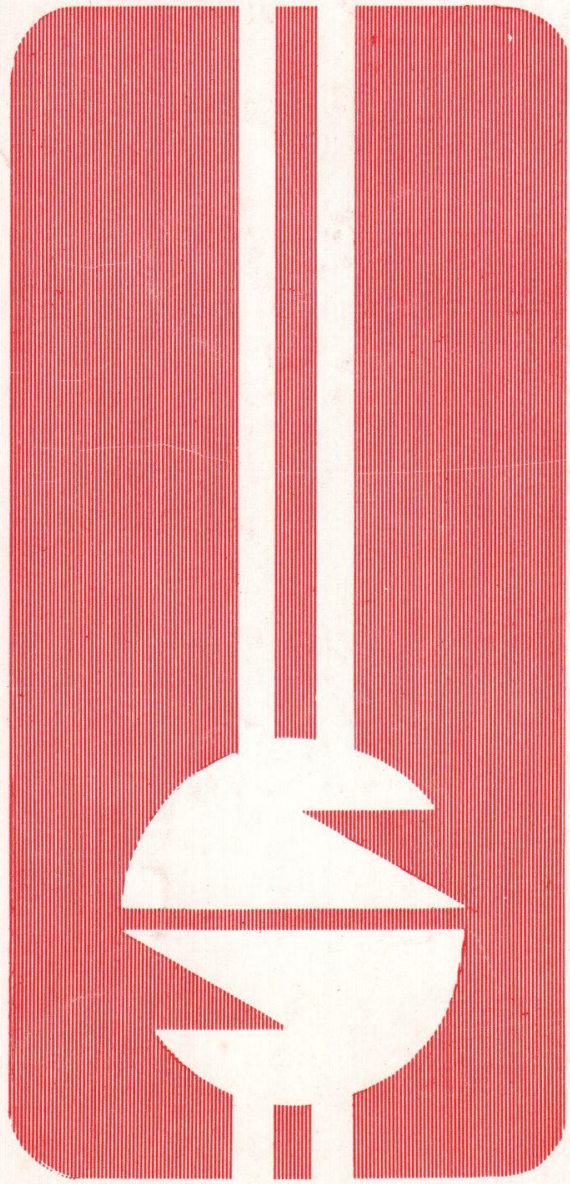
UNIVERSIDADE FEDERAL DO RIO GRANDE DO SUL

Reitor: Prof. Hélgio Henrique Casses Trindade

FACULDADE DE CIÉNCIAS ECONÔMICAS

Diretora: Prof ${ }^{a}$ Yeda Rorato Crusius

CENTRO DE ESTUDOS E PESQUISAS ECONÔMICAS

Diretor: Reinaldo Ignacio Adams

DEPARTAMENTO DE CIENNCIAS ECONÔMICAS

Chefe: Prof. Fernando Ferrari Filho

CURSO DE PÓS-GRADUAÇÃO EM ECONOMIA

Coordenador: Prof. João Rogério Sanson

CURSO DE PÓS-GRADUAÇÃO EM ECONOMIA RURAL

Coordenador: Prof. Juvir Luiz Mattuella

CONSELHO EDITORIAL: Achyles Barcelos da Costa, Aray Miguel Feldens, Atos Freitas Grawunder, Carlos Augusto Crusius, ErnaniHickmann, Fernando Ferrari Filho, João Rogério Sanson, Juvir Luiz Mattuella, Maria Imilda da Costa e Silva, Nali de Jesus de Souza, Nuno Renan Lopes de Figueiredo Pinto, Otília Beatriz Kroeĩ Carrion, Otto Guilherme Konzen, Paulo Alexaridre Spohr, Pedro Cezar Dutra Fonseca, Reinaldo Ignacio Adams, RobertsCamps Moraes, Valter José Stülp, Yeda Rorato Crusius, David Garlow (Wharton Econometrics Forecasts Association, E.U.A.), Edgar Augusto Lanzer (UFSC), Eleutério F. S. Prado (USP), Fernando Holanda Barbosa (FGV/RJ), Gustavo Franco (PUC/RJ), Joaquim Pinto de Andrade (UiNB), Juan H. Moldau (USP), Werner Baer (Univ. de Illinois, E.U.A.)

COMISSÃO EDITORIAL: Atos Freitas Grawunder, Reinaldo Ignacio Adams, Pedro Cezar Dutra Fonseca, Roberto Camps Moraes.

EDITOR: Nali Jesus de Souza

SECRETARIA: Maria Ivone de Mello (normalização), Vanete Ricacheski (revisão de textos)

FUNDADOR: Prof. Antônio Carlos Santos Rosa

Os materiais publicados na Revista Análise Econômica são de exclusiva responsabilidade dos autores. É permitida a reprodução total ou parcial dos trabalhos, desde que seja citada a fonte.

Aceita-se permuta com revistas congêneres. Aceitam-se, também, livros para divulgação, elaboração de resenhas ou recensões.

Toda correspondência, material para publicação (vide normas na $3^{a}$ capa), assinaturas e permutas devem ser dirigidos ao seguinte destinatário:

PROF. NALI DE JESUS DE SOUZA

Revista Análise Econômica

Av. João Pessoa, 52

90040-000 - PORTO ALEGRE (RS), BRASIL

Telefones: (051) 228.1633 - 224.6022 - Ramais 3348 ou 3440

FAX: (051) 225.1067 


\title{
POR QUE OS SINOS DOBRAM? CONFLITO TRABALHISTA E SALÁRIOS DO MAGISTÉRIO PÚBLICO DO RIO GRANDE DO SUL, 1974-1991*
}

\author{
Carlos Henrique Horn ** \\ Roberto Balau Calazans ***
}

\section{SINOPSE}

Discutem-se aqui as razŏes do conflito trabalhista entre o magistério público e o governo do estado do Rio Grande do Sul. Procura-se demonstrar que a exacerbação do conflito a partir de 1979 deveu-se, em larga medida, à deterioração salarial dos professores, em termos absolutos e relativos, que fomentou a insatisfação e gerou a propensão para a greve em um ambiente de maior liberdade política. Conclui-se que a reprodiļão de uma política de salários penalizadora do magistério deverá prolongar o conflito para o futuro

\section{INTRODUÇÃO}

Desde fins dos anos 70, quando o sindicalismo ressurgiu como movimento sccial no País, um particu'ar conflito trabalhista vem se repetindo no estado do Rio Grande do Sul com uma perseverança que não possui melhor ilustração do que a própria ação simbólica de seus principais atores ao repicarem os sinos na Praça da

* Os autores agradecem cos comentários de Bolivar Tarragó Moura Neto e Ingrid Schneider a uma versāo anterior deste artigo. Dada a natureza da revista Análise Econômica, subtraímos, na atual versão, as passagens de enfoque marcadamente conjuntuãal. Uma vez mais, convém lembrar que os comentaristas năo sāo responsáveis pelas opiniōes aqui emitidas. Agradecemos o auxílio de Luciane Costa Carpena na edição final do artigo.

* Economista do Departamento Internacional de Estatística e Estudos Sócio-Econômicos (DIEESE) e Professor do Departamento de Ciências Econômicas da UFRGS.

*conomista do DIEESE e Mestre em Economia (IEPE-UFRGS)

ANÁLISE ECONÔMICA

ANO 10

$\mathrm{N}: 18$

SETEMBRO/92

P.63-8I 
Matriz. A frequiência das greves do magistério público estadual tem levado parte da sociedade rio-grandense a desenvolver uma explicação fantástica segundo a qual os professores, hipnotizados por lideranças intransigentes e portadoras de interesses escusos, estariam acometidos pela "síndrome do grevismo".

Um aspecto surpreendente deste conflito trabalhista, posto que o processo já se estende por mais de dez anos, tem sido a ausência de análises menos impressionísticas sobre a questão salarial do funcionalismo público em geral e do magistério em particular. Os estudos sobre a situação financeira da administração direta do Estado tratam basicamente de analisar os salários como um agregado de despesa, sern dedicar maior atenção ao tema das diretrizes e resultados da política salarial do governo. Apenas subsidiariamente, e sem maior profundidade, faz-se alguma referência a essa temática.

Entre as parcas abordagens não-jornalísticas em que se encontram observações sobre a política de salários do governo estadual, con vém mencionar a análise de Guimarães sobre o agravamento das finanças públicas do Rio Grande do Sul no período de 1979 a 1986 (Guimarães, 1988). O autor, ao analisar as caus da deterioração financeira do Estado afirma que, contrariamente ao que se pode observar para o período anterior, a obtençäo de ganhos salariais e outras vantagens pelo funcionalismo, a partir de 1986, consistiria em fator adicional de piora das finanças públicas. De modo mais preciso, Guimarães indica que, neste ano,

(...) várias categorias funcionais (educação, segurança, Judiciário, Legislativo), que representam mais de $60 \%$ da despesa de pessoal, passaram a ter ganhos superiores à média dos vencimentos dos funcionários públicos e à taxa de inflação.

Assim, se as despesas com pessoal ativo e inativo não foram um fator agravante das finanças do setor público governamental no período de 1979 a 1985, passaram a sê-lo a partir de 1986

Todavia (...) isso é devido, preponderantemente, à concessão de vantagens e privilégios a determinadas categorias de servidores públicos (Guimarães, 1988, p. 122-3).

Ainda que a análise de Guimarães esteja fartamente ilustrada com agregados financeiros do setor público estadual consolidado, entre outros, ela ressente-se da ausência de um tratamento estatístico que evidencie suas afirmações quanto aos ganhos salariais de parcelas do funcionalismo. Convém assinalar, ademais que suas conclusões restringem-se ao ano de 1986, havendo apenas uma observação complementar sobre vantagens extras obtidas pelos funcionários civis e militares da segurança pública e que teriam efeito prático no ano de 1987. Assim, porque circunscrito ao período de 1979 a 1986, esse estudo não oferece uma base segura para conclusões acerca dos anos subseqüentes. No entanto, ao resenharem o artigo de Guimarães, Fraquelii e outros autores parecem ter incorrido em perigosa generalização. Eles afirmam:

A admissão de funcionários com ganhos superiores à média dos vencimentos, corrigidos segundo os indices de inflação, principalmente nas categorias funcionais, como educação, 
segurança, Judiciário, Legislativo, etc., e que representam, por si $s 6,60 \%$ da despesa de pessoal, e o aumento da taxa de crescimento das despesas com pessoal inativo, sobretudo a partir de 1986, em categorias especiais, como professores, pessoal militar (Brigada) e juízes, são razões fortes apontadas pelo autor para que a situaçāo financeira do Estado venha a piorar da em diante. (Fraquelli et alii, 1991, p.156, o grifo é nosso).

Dado o caráter altamente controverso do assunto, é necessário enfrentá-lo com rigor redobrado a fim de evitar as insuficiências e ambigüidades que conduzem a interpretações equivocadas. Nas linhas que seguem, procuramos demonstrar, a partir de uma investigação sobre o comportamento dos salários do magistéric público do Rio Grande do Sul entre 1974 e 1991, duas proposições: a) que o acirrado conflito entre o magistério e o governo estadual deve-se, em larga medida, à deterioração salarial dos professores, que fomentou a insatisfação e gerou a propensão para a greve; b) que, se houve concessão de vantagens e privilégios ao magistério, e não apenas em 1986, esta foi insuficiente para reverter a tendência ao empobrecimento suportado pelo professorado gaúcho.

\section{A EVOLUÇÃO DO SALÁRIO REAL DO MAGISTÉRIO ESTADUAL ENTRE 1974 E 1991}

O entendimento da motivação econômica do conflito trabalhista do magistério estadual requer uma análise da evolução do poder aquisitivo dos salários da categoria. Dado que o magistério público encontra-se organizado em quadro de carreira ${ }^{1}$, podemos realizar essa investigação com base no comportamento do seu vencimento básico. Isto porque os demais salários constituem múltiplos do vencimento básico segundo determinadas relações fixas. Explicando melhor: a carreira do magistério é estruturada em forma matricial, disposta em seis classes e em seis níveis de habilitação. As classes, designadas pelas letras A a F, compreendem uma linha de promoção por tempo de serviço e mérito, enquanto os níveis, identificados pelos números 1 a 6 , indicam diferentes graus de habilitação ou educação formal do quadro do magistério. Ac relações entre os salários de cada posição na cancira, entendida como um par classe-nível, são apresentadas na Tabela 1.

Como podemos perceber, toda a matriz salarial do magistério está vinculada à evolução do vencimento básico do quadro, que corresponde à classe A-nível 1. Os valores dos diversos níveis e classes consistem em múltiplos desse valor de referência, fazendo com que o comportamento desse parâmetro expresse a evolução do conjunto dos salários da categoria. Convém notar, contudo, que a possibilidade de ascensão do professor entre as classes e os níveis ao longo de sua carreira e os avanços trienais de salários propiciam um ganho independente da

1 A lei no 6.672. de 22.04.1974. implantou novo regime jurídico para o pessoal do magistério público estadual do primeiro e segundo graus de ensino e a Lei no 6.673, de 22.04.1974, fixou o vencimento básico e suas relaçōes com os demais vencimentos da carteira. Ver Scomazzon (1986) 
correção da matriz salarial. Assim, para sermos precisos, a evolução do vencimento básico evidencia a evolução da matriz salarial do magistério, isto é, do conjunto dos salários básicos, podendo cada professor individualmente construir uma particular trajetória salarial conforme sua linha de promoção e tempo de serviço.

\section{TABELA 1 \\ RELAÇÕES SALARIAIS DO QUADRO \\ DO MAGISTÉRIO PÚBLICO ESTADUAL}

\begin{tabular}{l|rrrrrr}
\hline \multirow{2}{*}{ Níveis } & \multicolumn{7}{|c}{ Classes } \\
\cline { 2 - 7 } & A & B & C & D & E & F \\
\hline 1 & 1,00 & 1,10 & 1,20 & 1,30 & 1,40 & 1,50 \\
2 & 1,15 & 1,26 & 1,38 & 1,49 & 1,65 & 1,72 \\
3 & 1,30 & 1,43 & 1,56 & 1,69 & 1,82 & 1,95 \\
4 & 1,50 & 1,65 & 1,80 & 1,95 & $-2,10$ & 2,25 \\
5 & 1,85 & 2,03 & 2,22 & 2,40 & 2,59 & 2,77 \\
6 & 2,00 & 2,20 & 2,40 & 2,60 & 2,80 & 3,00 \\
\hline
\end{tabular}

FONTE: Scomazzca (1986).

Tomando-se como referência a data de implantação do atual quadro de carreira ( $\left.1^{\circ} .01 .1974\right)$, construímos uma série do vencimento básico real entre 1974 e 1991. Os principais resultados estão expostos na Tabela 2, que compreende tanto o índice do vencimento básico real médio, quanto os valores praticados em cada ano a preços de dezembro de 1991. Na tabe!a, os índices representam médias anuais dos dados mensais, que, se comparados à base 100 , indicam a perda ou o ganho de salário real relativamente ao valor real na data de implantação do quadro de carreira. 
TABELA 2

EVOLUÇÃO DO VENCIMENTO BÁSICO REAL MÉDIO DO MAGISTÉRIO PÚBIICO DO RIO GRANDE DO SUL

1974-1991

\begin{tabular}{ccc}
\hline Ano & $\begin{array}{c}\text { Indice do Vencimento } \\
\text { Básico Real Médio } \\
\text { (Base 100=10.01.74) }\end{array}$ & $\begin{array}{c}\text { Valor do Vencimento } \\
\text { Básico a preços de } \\
\text { Dezembro de 1991 (Cr\$) }\end{array}$ \\
\hline 1974 & 83,28 & $257.376,86$ \\
1975 & 84,73 & $261.861,49$ \\
1976 & 78,41 & $242.320,98$ \\
1977 & 68,13 & $210.541,16$ \\
1978 & 67,28 & $207.939,46$ \\
1979 & 69,93 & $216.107,10$ \\
1980 & 61,46 & $189.955,85$ \\
1981 & 50,57 & $156.300,17$ \\
1982 & 74,65 & $230.716,27$ \\
1983 & 62,77 & $193.986,81$ \\
1984 & 47,10 & $145.566,30$ \\
1985 & 54,62 & $168.815,67$ \\
1986 & 56,17 & $173.607,79$ \\
1987 & 45,52 & $140.670,03$ \\
1988 & 33,42 & $103.283,31$ \\
1989 & 41,26 & $127.501,20$ \\
1990 & 38,22 & $118.129,10$ \\
1991 & 28,50 & $88.092,26$ \\
\hline
\end{tabular}

FONTE DOS DADOS BRUTOS: DIEESE - Subseção CPERS/Sindicato.

Obs. : 1. Os valores nominais do vencimento básico incluem abonos e parcelas autônomas

2. Deflator: IGP-DI-FGV.

Os dados da Tabela 2 evidenciam a queda tendencial do poder aquisituvo do magistéric desde a implantação do plano de carreira de 1974. Considerando-se os anos inicial e final da série, o salário foi reduzido a quase um terço do seu poder aquisitivo. Trata-se de um violento arrocho salarial, apenas contra-arrestado, para cada professor tomado individualmente, pela possibilidade de ascensão na linha de promoção do quadro de carreira e pelos avanços trienais de salário. Sem considerar que o uso das promoções e dos triênios como mecanismo de proteção do poder de compra representa uma perversão do próprio instituto, nada assegura, contudo, a eficácia desse mecanismo diante da intensidade da contração imposta à matriz salarial.

As Tabelas 3 e 4, por seu turno, apresentam, respectivamente, os maiores e menores valores reais mensais do vencimento básico. Podemos perceber, com 
base nos dados das tabelas, que o vencimento básico do magistério gaúcho já se encontrou em um patamar bastante superior ao de dezembro de 1991. Assim, o poder aquisitivode janeirode 1982, o maior doperíodo investigado, corresponderia a um vencimento básico 6,81 vezes superior ao vencimento vigente em dezembro de 1991. No mês de implantação do quadro de carreira, o vencimento básico representava um poder aquisitivo equivalente a $\operatorname{Cr} \$ 300.199,98$ a preços de dezembro de 1991.

Os dados da Tabela 4 demonstram que o ano de 1991 concentrou os menores valores reais mensais do vencimento básico. Em dezembro de 1991, quando foi praticado o menor valor real mensal, o poder de compra do vencimento básico correspondia a apenas $15,00 \%$ daquele fixado para a data de implantação do quadro de carreira.

\section{TABELA 3}

MAIORES VALORES REAIS MENSAIS DO VENCIMENTO BÁSICO DO MAGISTÉRIO DO RIO GRANDE DO SUL 1974-1991

\begin{tabular}{ccc}
\hline $\begin{array}{c}\text { Mês/ } \\
\text { Ano }\end{array}$ & $\begin{array}{c}\text { Índice do Vencimento } \\
\text { Básico Real } \\
\text { (Base 100 }=\mathbf{1 0}^{\mathbf{0 . 0 1 . 7 4}}\end{array}$ & $\begin{array}{c}\text { Valor do Vencimento } \\
\text { Básico a preços de } \\
\text { Dezembro de 1991 (Cr\$) }\end{array}$ \\
\hline Jan/82 & 102,09 & $315.464,91$ \\
$\operatorname{Jan} / 83$ & 98,41 & $304,093.46$ \\
$\operatorname{Jan} / 74$ & 97,15 & $300.199,98$ \\
\hline
\end{tabular}

FONTE DOS DADOS BRUTOS: DIEESE-Subseçâo CPERS/Sindicato.

Obs: 1 . Os valores nominais do vencimento básico incluem abonos e parcelas autônomas.

2. Deflator: IGP-DI-FGV.

TABELA 4

MFNORES VALORES REAIS MENSAIS DO VENCIMENTO BÁSICO DO MAGISTÉRIO DO RIO GDANDE DO SUi.

1974-1991

\begin{tabular}{ccc}
$\begin{array}{c}\text { Mês/ } \\
\text { Ano }\end{array}$ & $\begin{array}{c}\text { Índice do Vencimento } \\
\text { Básico Real } \\
\text { (Base 100 }=\mathbf{1}^{\mathbf{0} .01 .74)}\end{array}$ & $\begin{array}{c}\text { Valor do Vencimento } \\
\text { Básico a preços de } \\
\text { Dezembro de 1991 (Cr\$) }\end{array}$ \\
\hline Dez/91 & 15,00 & $46.351,00$ \\
Mar/91 & 19,15 & $59.174,78$ \\
Fev/90 & 20,19 & $62.388,45$ \\
Fev/91 & 20,54 & $63.469,97$ \\
\hline
\end{tabular}

FONTE DOS DADOS BRUTOS: DIEESE-Subseção CPERS/Sindicato.

Obs: 1 . Os valores nominais do vencimento básico incluem abonos e parcelas autônomas.

2. Deflator: IGP-DI-FGV. , 
A evolução do vencimento básico real constitui uma forte indicação de que a raiz dos conflitos que marcaram as relações entre o magistério e o governo estadual a partir de fins dos anos 70, tendo como pano de fundo um maior grau de liberdade política, está relacionada à queda tendencial do poder aquisitivo dos salários. A Figura 1, a par de permitir uma clara visualização da tendência declinante do salário real, evidencia que os ciclos de greves do magistério representaram, afora outras determinações, uma reação à perda salarial imposta ao professorado. Assim, as greves de 1979-80 compreenderiam uma tentativa de recuperação salarial após a trajetória cadente de 1975-78. Desconsiderando-se o ano de 1982, em que a greve durou apenas dois dias, um novo ciclo foi aberto em 1985 , como resposta à forte queda salarial de 1983-4, prolongando-se no período de 1987-91, em que a redução do salário real foi praticamente contínua.

A análise da relação entre o salário real e a duração cias greves do magistério fornece uma indicação adicional da primazia da motivação econômica dos conflitos. Na Tabela 5, apresentamos algumas informações sobre as greves dos professores, acompanhadas do índice do vencimento básico real efetivamente praticado no mês de deflagração da greve. ${ }^{2}$ Os dados respectivos do índice de vencimento real e da duração da greve foram plotados na Figura 2, que permite identificar uma certa correlação entre a extensão da greve e o poder de compra dos salários. O coeficiente de correlação linear é de $-0,5797$ para todos os anos e de $-0,8180$ se excluirmos o ano de 1988 . Vale dizer, para o período de 1979-91, a intensidade do movimento paredista do magistério foi inversamente proporcional ao nível do seu salário real.

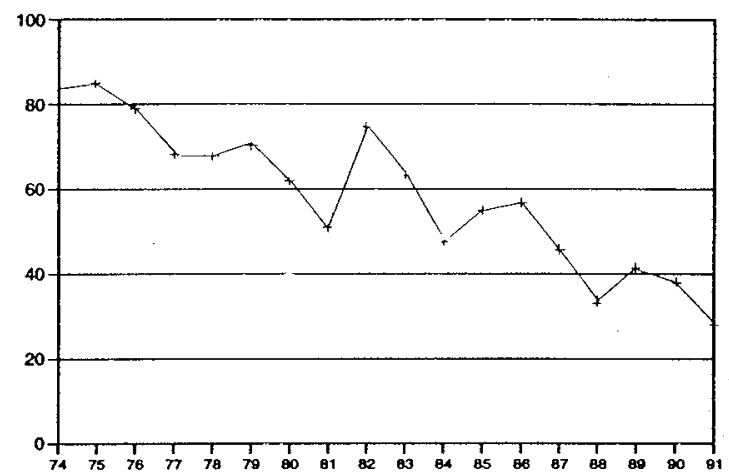

FIGURA 1 - Evolução do índice do vencimento básicu real médio do magistério do Rio Grande do Sul (1974-1991)

2 O índice do vencimento real efetivamente praticado no mês de deflagração da greve, por năo levar em conta ganhoś resultantes da barganha para vigorarem retroativamente a esse mês ou mesmo a um período anterior, expressa o poder aquisitivo dos professores quando colocados diante da questão de deflagrar ou não um movimento paredista. 
TABELA 5

DURAÇÃO DAS GREVES E INDICE DO VENCIMENTO BÁSICO REAL EFETIVO DO MAGISTÉRIO DO RIO GRANDE DO SUL

1979-1991

\begin{tabular}{cccc}
\hline Ano & $\begin{array}{c}\text { Data de Início } \\
\text { e de Término } \\
\text { da Greve }\end{array}$ & $\begin{array}{c}\text { Duração } \\
\text { Greve } \\
\text { (em Dias) }\end{array}$ & $\begin{array}{c}\text { Indice do Vencimento } \\
\text { Básico Real Efetivo } \\
\text { no Mês de Início da Greve }\end{array}$ \\
\hline 1979 & 05.04 a 17.04 & 13 & 72,39 \\
1980 & 30.10 a 19.11 & 21 & 50,54 \\
1982 & 02.03 a 03.03 & 2 & 89,09 \\
1985 & 10.05 a 09.07 & 60 & 46,59 \\
1987 & 10.04 a 14.07 & 96 & 37,23 \\
1988 & 17.10 a 25.10 & 9 & 24,05 \\
1989 & 17.05 a 27.06 & 42 & 41,48 \\
1990 & 08.05 a 04.07 & 58 & 27,51 \\
1991 & 08.03 a 20.05 & 73 & 19,15 \\
\hline
\end{tabular}

FONTE DOS DADOS BRUTUS: DIEESE-Subseção CEPERS/Sindicato.

Obs.: 1. Os valores nominais do vencimento básico incluem abonos e parcelas autônomas.

2. Deflator: IGP-DI-FGV

3. fndice base $100=1^{\circ} .01 .1974$.

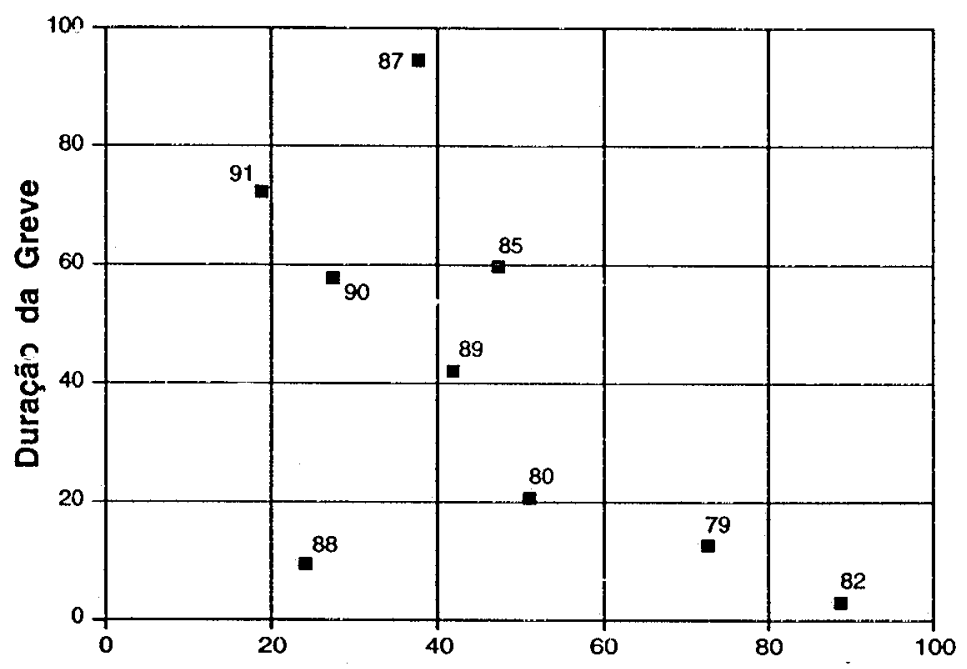

Básico no mês inicial da greve

FIGURA 2 - Duração das greves e índice do vencimento básico real efetivo do magistério do Rio Grande do Sul. (1979-1991). 
Insistamos no seguinte ponto: o conflito entre o magistério e o governo estadual, expresso nas greves deflagradas a partir de 1979 e que se exacerbaram no período 1987-91, constitui o resultado insofismável do arrocho salarial a que foi submetido o professorado gaúcho ao longo desses anos. Neste conflito, o magistério diferencia-se de outras categorias do funcionalismo público estadual, quer pela sua capacidade de organização e mobilização, quer pela necessidade mesma de utilizar a greve como um instrumento de pressão diante da particular conduta do governo estadual na barganha.

Dada a contínua queda do poder aquisitivo dos salários, é quase redundante, para não dizer ingênuo, acusar o magistério de "radicalismo". Quando essa acusação dirige-se ao CPERS, ela revisita uma permanente polêmica sobre a ação sindical ${ }^{3}$ Neste sentido, vale recuperar o alerta de Joan Robinson, ao comentar sobre as demandas de salário monetário dos sindicatos e seus efeitos sobre os preços e o poder de compra dos assalariados. Ela assevera que, independente do resultado,

(...) permanece a obrigação de cada sindicato, individualmente, de cuidar dos interesses de cada um de seus membros. Apelar para qualquer sindicato para que exerça o espírito público e restrinja as exigência salariais é apelar para que traia a sua confiança (Robinson, 1979, p.155).

No caso concreto do magistério gaúcho, as observações de Joan Robinson são particularmente apropriadas. A dinâmica das decisões da categoria nas campanhas salariais, através das discussões nos núcleos do CPERS e das assembléias gerais, garante um elevado grau de aderência entre o desejo do professorado e a conduta de sua liderança. Diante do tratamento habitualmente dispensado pelos governos estaduais à remuneração dos professores, se a liderança viesse a reduzir as demandas salariais - demandas de recomposisão do salário real, enfatizemos ou a manter, no processo de barganha, um comportamento contrário às expectativas da sua base, isso seria percebido como uma traição aos membros do sindicato e redundaria na perda de legitimidade da liderança.

\section{O MOVIMENTC DOS SALÁRIOS RELATTVOS E A VALORAÇÃO SUBJETIVA DOS PROFESSORES}

Ainda que as evidências acerca do salário real forneçam uma base segura para que demonstremos a motivação econômica do conflito trabalhista do magistério, indicações adicionais de que estaria havendo uma redução tendencial

3 Odiário Zero Hora tem sido especialmente profícuo na disseminação de uma mentalidade anti-sindical Durante o movimento paredista de 1991, a linha editorial do diário concentrou-se nas acusaçōes de que o movimento do magisterio gaúcho estaria contaminado pelo corporativismo e radicalismo de suas lideranças, denominadas "títeres do CPERS" (Zero Hora, 27.09.1991, p.2). As relaçōes entre a imprensa monopolista e os movimentos sociais no Rio Grande do Sul ainda estāo por receber um tratamento analítico adequado entre os cientistas sociais do Estado. 
dos vencimentos da categoria vis-à-vis os demais servidores ativos do Estado, aliadas ao próprio nivel da relação, reforçam a proposição central deste artigo. Como é sabido, existe uma farta literatura destacando a relevância das comparações no mundo do trabalho e de como elas afetam as disposições comportamentais dos trabalhadores. Ross (1983), por exemplo, refere-se à prática sindical como se movendo em órbitas de comparações coercitivas. Ele afirma:

As comparações são cruciais no mundo sindical, em que sempre se examinam detalhadamente os acordos salariais em processo de negociação e os já negociados. Elas revelam se um sindicato fez tão bem quanto outro, se um comitê negociador realizou um trabalho de negociação suficientemente qualificado. Demonstram ao membro do sindicato se está obtendo algo em troca de sua contribuição financeira. Uma comparação favorável ('o melhor contrato da indústria') constitui um argumento para a reeleição dos dirigentes, uma base para a consolidação e ampliação do sinđicato e uma ocasião para o avanço de novas lideranças dentro da hierarquia oficial. Uma comparação desfavorável ('o melhor que se pode alcançar nas circunstâncias dadas') torna provável o descontentamento da base, permite aos líderes rivais ganharem popularidade e ativa os sindicatos concorrentes (Ross, 1983, p. 162-3, a tradução é nossa).

Outro c $\sharp$ hecido autor observa que um sentimento de injustiça por parte dos trabalhadores fomenta pressões de salário, principalmente em face de alteração prévia nos salários relativos ou sistema de salários (Hicks, 1987). A importância da noção de salário relativo, diga-se de passagem, constitui uma das proposições centrais de Keynes sobre a determinação dos salários nominais. Amadeo Swaelen (1982) enfatiza que

A determinação do salário nominal de acordo com a formulação da G.T. (Teoria Gerah) depende fundamentalmente do diferencial entre níveis de salários de vários grupos de trabalhadores. Os trabalhadores nāo podem determinar o nível de salários reais mas procuram manter estável a relação entre os seus salários (isto é, salários na sua indústria) e os salários de trabalhadores de outras indústrias.

A tese de Keynes quanto à determinação dos salários nominais é, portanto, de que existe um forte efeito-demonstraçào entre diferentes grupos de trabalhadores (Amaueo Swaelen, 1982 , p.29)

Covém, por conseguinte, investigarmos o movimento dos salários relativos do magistério, se ele justificaria a elevada propensão à greve observada nos anos 80. A Tabela 6 apresenta a evolução do salário médio dos servidores ativos da Secretaria de Educação comparativamente ao salário dos servidores ativos da administração direta, em maio de cada ano. A escolha dos salários dos servidores ativos como parâmetro de comparação deve-se à conviç̧ão de que é a principal referência para os julgamentos dos professores acerca da justeza ou não da sua situação salarial, sem que isso signifique negar a existência de outros parâmetros. 
A ênfase nos salários dos servidores ativos relaciona-se ao fato de que eles revelam as opções do empregador comum, responsável pelo pagamento e com o qual se estabelece a barganha. Quanto ao uso do salário médio dos servidores da Secretaria de Educação, que expressa a remuneração dos professores e dos funcionários de escola, ele é um indicador adequado dos vencimentos do magistério que responde pela quase totalidade do emprego no órgão.

\begin{tabular}{|c|c|}
\hline Ano & Indicador de Salário Relativo ${ }^{1}$ \\
\hline 1975 & 86,74 \\
\hline 1976 & 86,13 \\
\hline 1977 & 86,83 \\
\hline 1978 & 87,74 \\
\hline 1979 & 85,76 \\
\hline 1980 & 86,67 \\
\hline 1981 & 83,20 \\
\hline 1982 & 92,70 \\
\hline 1983 & 93,86 \\
\hline 1984 & 93,23 \\
\hline 1985 & 84,49 \\
\hline 1986 & 82,08 \\
\hline 1987 & 85,27 \\
\hline 1988 & 87,13 \\
\hline 1989 & 74,04 \\
\hline 1990 & 81,50 \\
\hline
\end{tabular}

FONTE DOS DADOS BRUTOS: Finanças do Estado, vol.XXXIV, 198 ร

Finanças do Estado, vol.XXXVI, $198 \%$.

Finanças do Estado, vol.XXXIX, 1990.

Obs.: 1 . Os dados referem-se à situação de maio de cada ano.

Uma constatação que salta imediatamente aos olhos quando observamos a tabela é que os salários dos servidores da educação mantiveram-se abaixo da média dos servidores ativos da administração direta durante todo o período. Antes de prosseguirmos, cabe destacar que o fato de os dados circunscreverem-se a um único mês do ano pode produzir um viés na análise, uma vez que os ajustes salariais do funcionalismo distribuem-se desigualmente em diferentes pontos do tempo. Assim, melhor seria dispor de valores anuais para se chegar a uma conclusão mais segura. Uma tentativa de se obter um indicador anual, ainda 
sujeita a correções, consiste em calcula-lo com base na participação dos gastos anuais de pessoal ativo da Secretaria de Educação no total das despesas de pessoal ativo da administração direta e no nível de emprego de cada ano, conforme se demonstra nas seguintes equações. ${ }^{4}$ Seja a participação PGP:

$$
P G P=G P A S E / G P A A D
$$

Onde: PGP = Participação do Gasto Anual de Pessoal Ativo da Secretaria de Educação no Gasto de Pessoal Ativo da Administração Direta.

GPASE = Gasto Anual de Pessoal Ativo da Secretaria de Educação.

GPAAD = Gasto Anual de Pessoal Ativo da Administração Direta.

Sabendo-se que o valor agregado do gasto é igual ao produto do salário médio pelo nível de emprego, definimos uma nova equação para PGP:

$$
P G P=W S E . N S E / W A D . N A D
$$

Onde: WSE = Salário Médio da Secretaria de Educação.

NSE = Pessoal Ativo Total da Secretaria de Educação.

WAD = Salário Médio da Administração Direta.

NAD = Pessoal Ativo Total da Administração Direta.

Fazendo WREL $=$ WSE/WAD, o indicador de salário relativo do magistério, e $\mathrm{PN}=\mathrm{NSE} / \mathrm{NAD}$, a participação dos servidores ativos da Secretaria de Educação no emprego total da administração direta, temos:

$$
W K E L=P G P / P N
$$

Podemos, assim, calcular um indicador de salário relativo a partir dos dados de participação nos gastos de pessoal e de emprego. Os resultados obtidos estão expostos na Tabela 7.

4 O fato de dispor apenas dos dados de emprego para maio força-nos a adotar a suposição de que onivel de emprego relativo em cada ano corresponde ao nível desse mês. A divulgação da série completa do emprego permitiria identificar o desvio decorrente dessa suposição. Uma discussão mais ampla sobre os problemas de construçāo de indicadores de salários relativos e de sua interpretaçăo envolveria consideraçōes sobre as alteraçōes na estru:"'ra ocupacional, entre outras, fugindo ao escopo do nosso estudo. 


\section{TABELA 7 \\ INDICADOR DE SALÁRIO RELATIVO DO MAGISTÉRIO \\ COMPOSIÇÃO DA DESPESA DE PESSOAL ATTVO E DO EMPREGO E RELAÇÃO ENTRE SALÁRIOS MÉDIOS DOS SERVIDORES ATIVOS DA SECRETARIA DE EDUCAÇÃO E DA ADMINISTRAÇÃO DIRETA 1975-1989}

(\%)

\begin{tabular}{cccc}
\hline Ano & PGP & PN & WREL \\
\hline 1975 & 56,20 & 69,82 & 80,49 \\
1976 & 57,75 & 71,63 & 80,62 \\
1977 & 59,49 & 72,70 & 81,83 \\
1978 & 57,17 & 73,03 & 78,29 \\
1979 & 54,94 & 73,75 & 74,49 \\
1980 & 54,96 & 73,48 & 74,79 \\
1981 & 55,02 & 73,27 & 75,10 \\
1982 & 54,46 & 71,92 & 75,72 \\
1983 & 56,06 & 71,31 & 78,62 \\
1984 & 46,91 & 72,12 & 65,05 \\
1985 & 47,50 & 71,69 & 66,25 \\
1986 & 50,13 & 71,00 & 70,61 \\
1987 & 52,61 & 71,56 & 73,52 \\
1988 & 48,43 & 70,48 & 68,71 \\
1989 & 49,91 & 70,07 & 71,23 \\
\hline
\end{tabular}

FONTE DOS DADOS BRUTOS: Finanças do Estado, vol.XXXIY, 1985.

Finanças do Estado, vol.XXXVI, 1987.

Finanças do Estado, vol.XXXIX, 1990.

Os dados da Tabela 6, que passamos a designar por método 1 , discrepam dos dados da Tabsla 7, referido como método 2. Em comum, ambos os métodos indican que o salário médio dos servidores ativos da Secretaria de Educação permaneceu aquém do salário médio do total de funcionários ativos da administração direta, o que revela uma determinada opção cie política salarial dos governos que se sucederam entre 1974 e 1991. Na Figura 3, podemos visualizar a trajetória do indicador de salário relativo conforme cada um dos métodos. Passando ao largo das flutuações, parece correto concluir que a tendência do salário relativo do magistério é declinante ao longo do período abrangido, ainda que num ritmo substancialmente menor do que o do vencimento básico real. As oscilações do indicador apontam para uma determinada periodização. Um comportamento entre constante e levemente declinante é verificado nos anos de 1975 a 1981, ainda que se observe uma pequena recuperação desde 1979 com base no método 2 . O biênio 1982-83 revela um ganho de salário relativo do magistério, quando se atinge, segundo o método 1, o pico para a totalidade do período investigado. Segue-se o 
ano de 1984, que marca a perdado espaço conquistado e o estabelecimento de novo patamar para o salário relativo segundo o método 2. Cabe assinalar que esse movimento ocorre apenas em 1985 se medido pelo método 1. De fato, parece haver uma certa defasagem de comportamento conforme se mensure o salário relativo pelo método 1 ou 2, o que não deve suscitar maiores preocupações. Em sendo o método 2 correspondente ao ano inteiro, é razoável que ele antecipe o movimento de maio do ano seguinte, medido pelo método 1. Após o tombo de 1984-85, o salário relativo volta a recuperar-se até 1987-88, para observar nova redução em 1988-89. Para o ano de 1990, verifica-se um novo crescimento de acordo com o método 1 , já detectado em 1989 com base no método 2 .

Uma vez mais parece comprovar-se a existência de uma nítida correlação entre os movimentos paredistas do magistério e o comportamento dos salários. Assim, podemos notar que o ciclo de greves de 1979-80 sucede um período de redução do salário relativo da categoria, tanto quanto os ciclos de 1985 e 1987-91 podem ter sido sobredeterminados pela perda da posição atingida em 1982-83. Não por acaso, os anos de calmaria de 1981-84 combinam-se, ainda que de modo imperfeito, com a significativa melhoria salarial do magistério.

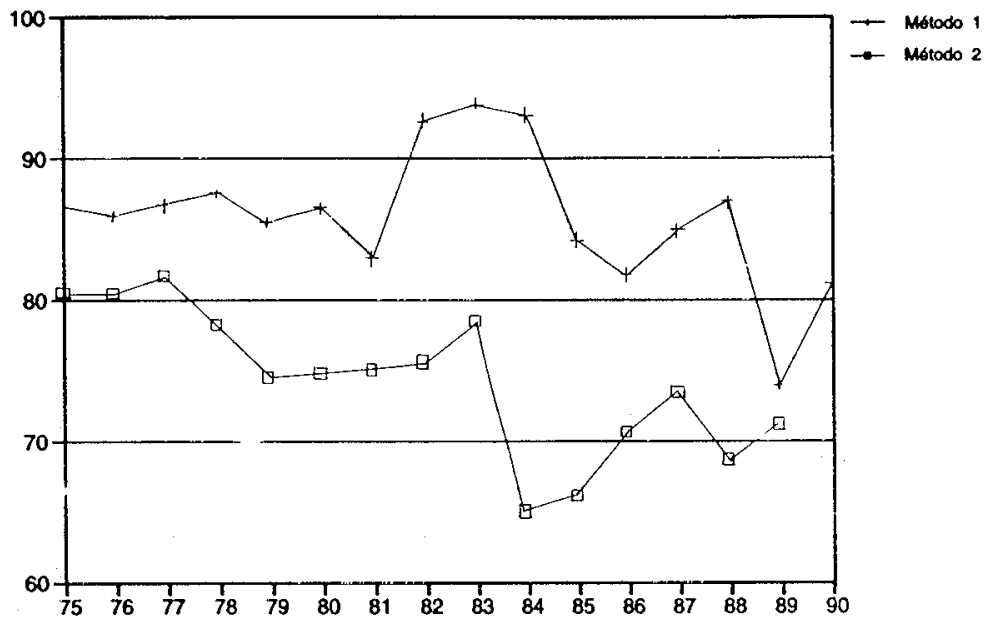

FIGURA 3 - Indicadores de salário relativo do magistério (1975-1990).

Por sua vez, a percepção dos professores quanto à sua posição na estrutura salarial da administração direta deve ter sido negativamente afetada, ao longo de todo o período, pelo fato de a média salarial da Secretaria de Educação ter-se mantido abaixo do nível médio dos servidores ativos. Se levarmos em consideração a estrutura de salários médios relativos da administração direta em maio de 
1990, o salário médio da Secretaria de Educação ocupava a posição 21 entre 23 órgãos. ${ }^{5}$ A Tabela 8 apresenta diferentes relações entre o salário médio em cada órgão da administração direta e o salário médio total, dos ativos e da Secretaria de Educação, respectivamente.

\section{TABELAA 8 \\ INDICADORES DE SALÁRIO RELATIVO NA ADMINISTRAÇÃO DIRETA DO RIO GRANDE DO SUL MAIO/1990}

\begin{tabular}{|c|c|c|c|c|}
\hline \multirow[t]{2}{*}{ Órgão } & \multirow{2}{*}{$\begin{array}{c}\text { Número } \\
\text { de } \\
\text { Ordem }\end{array}$} & \multicolumn{3}{|c|}{$\begin{array}{l}\text { Relação entre o salário médio } \\
\text { no órgão e o salário médio }\end{array}$} \\
\hline & & Total & Ativos & Sec. Educação \\
\hline Proc. Geral da Justiça & 1 & 5,58 & 6,08 & 7,46 \\
\hline Tribunal de Alçada & 2 & 2,68 & 2,92 & 3,60 \\
\hline Assembléia Legislativa & 3 & 2,64 & 2,88 & 3,53 \\
\hline Tribunal de Contas & 4 & 2,58 & 2,81 & 3,45 \\
\hline Proc. Ge :sel do Estado & 5 & 2,50 & 2,73 & 3,35 \\
\hline Sec. Fazenda & 6 & 2,32 & 2,53 & 3,11 \\
\hline Justiça Militar & 7 & 2,21 & 2,41 & 2,96 \\
\hline Tribunal de Justiça & 8 & 1,65 & 1,81 & 2,21 \\
\hline Sec. do Planejamento & 9 & 1,39 & 1,52 & 1,86 \\
\hline Juizado de Menores & 10 & 1,37 & 1,49 & 1,83 \\
\hline Gabinete do Governador & 11 & 1,36 & 1,48 & 1,82 \\
\hline Sec. de Segurança & 12 & 1,23 & 1,34 & 1,65 \\
\hline Inativos e Pensionistas & 13 & 1,18 & 1,29 & 1,58 \\
\hline Sec. Indústria e Comércio & 14 & 1,17 & 1,27 & 1,56 \\
\hline Sec. Energia e Minas & 15 & 1,12 & 1,22 & 1,49 \\
\hline Sec. Justiça & 16 & 1,10 & 1,20 & 1,47 \\
\hline Sec. Trabalho & 17 & 0,95 & 1,03 & 1,27 \\
\hline Sec. Transportes & 18 & 0,87 & 0,95 & 1,16 \\
\hline Sec. Interior & 19 & 0,85 & 0,93 & 1,14 \\
\hline Sec. Recursos Humanos & 20 & 0,78 & 0,85 & 1,04 \\
\hline Sec. Educação & 21 & 0,75 & 0,82 & 1,00 \\
\hline Sec. Saúde & 22 & 0,76 & 0,77 & 0,94 \\
\hline Sec. Agricultura & 23 & 0,70 & 0,76 & 0,94 \\
\hline
\end{tabular}

FONTE DOS DADOS BRUTOS : Finanças do Estado, vol XXXIX, 1990.

5 Os inativos e pensionistas foram considerados como equivalendo a um órgão específico. 
A Figura 4 expõe o indicador que relaciona o salário médio em cada órgão da administração direta e o salário médio na Secretaria de Educação. As relações são ordenadas da maior para a menor, permitindo visualizar a distância entre os vencimentos do magistério e dos demais servidores.

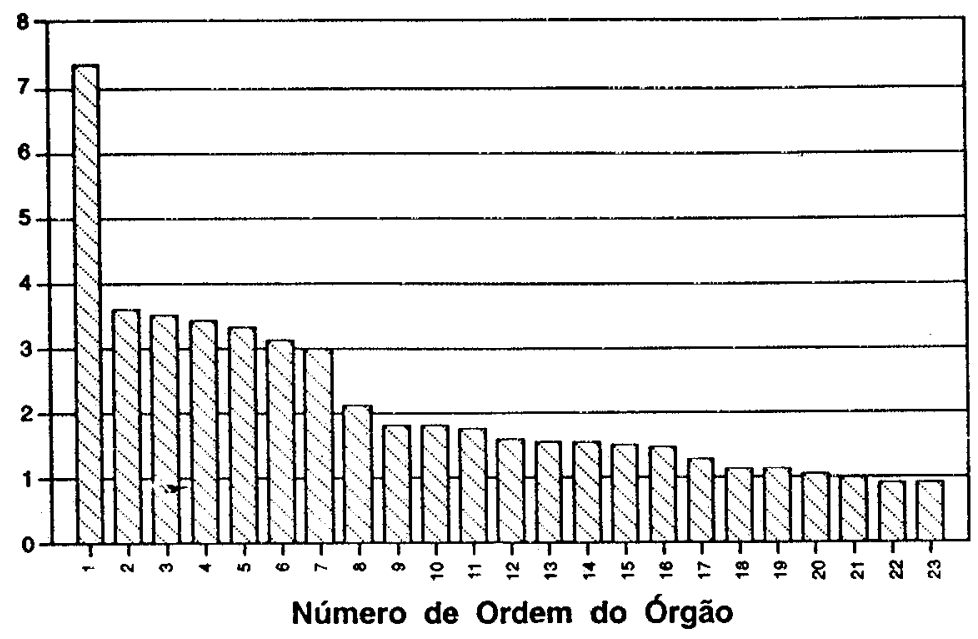

FIGURA 4 - Relação entre salário médio no órgão e salário médio na Secretaria de Educação (maio/1990)

Para finalizar essa investigação sobre o movimento dos salários relativos, cabe um breve comentário sobre algumas diferenças entre a barganha salarial do magistério e de outros segmentos específicos da administração direta. Devido ao fato de o magistério representar uma substancial parcela do funciozalismo, portanto, das despesas de pessoal da administração direta, a barganha salarial da categoria está marcada por uma maior rigidez do governo quanto a concessões, uma vez que um ponto percentual de reajuste dos vencimentos do magistério apresenta uma repercussão financeira superior à de outros segmentos tomados individualmente. A par de tornar relativamente mais transparentes as negociações, essa rigidez acaba por precipitar a barganha entre o governo to magistério para o ponto do confronto. Em contrapartida, as concessões para categorias numericamente menores não requerem negociações transparentes, muitas vezes sequer prolongadas. Além dessa diterença numérica, uma outra afeta a barganha correspondente ao magistério, de um lado, e a determinadas categorias do funcionalismo, de outro. Trata-se de sua particular inserção na máquina governamental e de como essa inserção lhe confere um particular poder de barganha. Assim, no caso de impasse, o instrumento final de sanção de que dispõe o magistério é a greve, 
enquanto outras categorias podem exercer pressão por meio de instrumentos que sequer exigem sua mobilização aberta. Que dizer, por exemplo, da ameaça de uma atividade menos eficiente na fiscalização de tributos ou na defesa dos interesses da administração pública nos tribunais? Porém, uma vez concedidos, a determinados segmentos, os ganhos salariais que "não possuem repercussão financeira significativa" (a expressão nãoé nossa), a massa de salários dos grupos mais numerosos do funcionalismo, neles incluído o magistério, torna-se uma variável de ajuste das finanças do Estado. ${ }^{6}$

\section{NO FUTURO, CONFLITO OU CONCERTAÇÃO?}

Ao longo deste artigo, procuramos demonstrar que os repetidos conflitos trabalhistas envolvendo o magistério e o governo estadual têm sua explicação relacionada sobretudo ao rebaixamento do salário real e do salário relativo dos professores, conjugando-se as situações de greve aos momentos de queda do poder aquisitivo dos salários. Regra geral, a política de salários levada a cabo pelos diferentes governos desde 1974 tem resultado, sob condições de aceleração inflacionária, no declínio tendencial do poder aquisitivo do magistério, até atingir-se odramático patamar do ano de 1991, quando se observaram os menores vencimentos desde a implantação do atual quadro de carreira.

A análise do comportamento dos salários - amparada em um tratamento estatístico mais amplo - permite-nos evidenciar a insuficiência, senão que o equívoco mesmo, de interpretações fundadas exclusivamente na análise agregada da despesa de pessoal. Especificamente, por não investigarem os dados sobre a evolução salarial de categorias particulares de servidores públicos, análises deste tipo não são capazes de sustentar afirmações quanto a "vantagens ou concessões salariais" distribuídas de forma desigual. Neste sentido, enfatizamos a necessidade de uma análise desagregada do comportamento dos salários do funcionalismo como forma de se examinarem as implicações da política salarial encetada pelo governo do Estado, não voltada apenas ao poder de compra dos salários, mas também ao nível e evoluç̃̃o dos salários réiativos, identificando, assim, as categorias beneficiadas e penalizadas pela política de salários.

Encarado mais amplamente, o particular confronto entre o governo e o magistério estadual resulta, ao fim e ao cabo, uma faceta do desinvestimento em educação, refletida nas trajetórias dos salários real e relativo dos profisssores. $O$ conflito trabalhista entre estes atores sociais e o fenômeno do desinvestimento em educação não se limitam, contudo, ao estado do Rio Grande do Sul. Apenas

6 A lógica e os desdobramentos dả barganha salarial, explícita ou velada, dos vários segmentos do funcionalismo público do Rio Grande do Sul mereceria uma profunda discussão que foge ao alcance deste artigo. Uma discussão dessa natureza poderia esclarecer as razöes que fizeram, por exemplo, as negocią̧ōes entre oCPERS eo governo, em junho de 1991, encerrarem-se sem a definição de uma política de salários para o magistério, ao passo que os servidores da Secretaria da Fazenda dispunham, há algum tempo, de regras próprias que thes asseguravam reajustes praticamente mensais de salário. 
a título de ilustração, convém mencionar que, ao longo de 1991, o jornal Folha de São Paulo publicou, sob o título de "A república da Ignorância", uma série de reportagens sobre a educação no País. Nelas, a carência geral de escolas e de professores, entre outros problemas que afligem todos os níveis da educação formal, indicariam a falência do sistema educacional, principalmente do segmento gerido pelo Estado. Em consequiência, observa-se uma insuficiente preparação da população e a escassez de pesquisas necessárias à inserção favorecida do País no processo de aceleração da revolução tecnológica, de intensificação da concorrência e de mudanças no mercado mundial, entre outras mazelas apontadas pelo jornal.

Em geral, a deterioração das condiçōes materiais de vida dos professores inscreve-se em determinadas estratégias visando ao equilíbrio das finanças públicas, em que o salário dos professores é eleito como variável de ajuste das despesas. Ora, essa forma de ajustamento produz efeitos negativos no médio prazo - de fato, já vivemos o médio prazo de decisões irresponsáveis do passado - pois implica a crescente desqualificação do ensino fundamental e impede a realiz ção dos vínculos entre o desenvolvimento do sistema educacional, a preparação dos recursos humanos e a satisfação das necessidades da sociedade.

Portanto, a permanecerem as práticas decorrentes do diagnóstico de que a despesa com o magistério representaria a principal variável de ajuste dodesequilíbrio financeiro do Estado, sobretudo quando o ônus do ajustamento é distribuído de forma desigual, a perspectiva é de que o conflito se prolongue para o futuro. Assim, por exemplo, levando-se em conta a diretriz manifestada na proposta orçamentária apresentada pelo governo estadual para 1992 e a persistência da Secretaria de Educação em modificar o quadro da carreira do magistério, é bastante provável a reprodução do impasse característico do período recente, porque a motivaçâo econômica apresentar-se-á de maneira ainda mais aguda. Embora a intenção governamental explicitada na proposta orçamentária indique o endureciemnto de sua posição na barganha, convém enfatizar que a trajetória das relações entre o governo e o magistério não está dada a priori, porque outras determinações de natureza política podem incidir no curso dos acontacimentos, condu/indo-os para a concertação ou para o confronto. Neste campo, um aspecto decisivo relacionase à necessidacie de remoção da desconfiança nutrida por parcela ponderável do magistério em relação ao governo, e que foi gerada, ao longo dos sucessivos embates entre as partes, pela ausência de uma opção governamental pe!a negociação efetiva.

Do ponto de vista econômico, contudo, não resta dúvida quanto aos riscos do conflito. Ainda que a situação de arrocho salarial do magistério esteja plenamente comprovada, outra e mais complexa questão é aquela que envolve a recuperação salarial. Não apenas porque circunscrita à capacidade de pagamento do Estado, que lhe fornece limites, mas sobretudo porque exige determinadas opções de política salarial do governo, isto é, uma decisão sobre a estrutura salarial da administração direta orientada pelas prioridades de governo. 
Para concluir, vale lembrar que a questão salarial do magistério não se circunscreve ao interesse individual dos professores, pois, conforme alerta Belluzzo, "hoje, felizmente, o dilema é educar ou perecer" (Belluzzo, 1991). O risco de novos confrontos entre o magistério e o governo estadual exige uma posição ativa da sociedade quanto ao problema da educação no sistema estatal. A solução do problema requer, com efeito, a recuperação salarial dos professores, ou seja, uma opção consciente pela distribuição de renda em favor de uma categoria específica de trabalhadores por causa de sua particular inserção na divisão do trabalho. Uma recuperação salarial, todavia, inserida necessariamente no âmbito de uma profunda reforma educacional - reforma esta que "deve começar por uma ação de convencimento da sociedade de que educar é uma tarefa pública e não apenas um encargo do Estado. (...) Pública significa que a família, a empresa, o sindicato e o Estado devem dividir a tarefa de educar, nos âmbitos de sua competência. Ao Estado cabe, sobretudo, universalizar o ensino básico e garantir a igualdade de oportunidades no ingresso na universidade" (Belluzzo, 1991).

\section{BIBLIOGRAFIA}

AMADEO SWAEL.EN, Edward Joaquim. Desemprego, Salários e Preços: um Estudo Comparativo de Keynes e do Pensamento Macroeconômico da Década de 70. Rio de Janeiro: BNDES, 1982

BEI L.UZZO, Luiz Gonzaga de M Educação, Tarefa de Toda a Sociedade. Isto é Senhor, nº 1.121, 20 março, 1991.

FRAQUEL.L., Antonio Carlos C. et ali. O Produto do Setor Público e as Despesas com Pessoal na Administração Direta do Governo Estadual Indicadores Econômicos FEE, Porto Alegre: FEE, v. 19. nº 1.p. 139-75, jun. 1991. •

GUIMARÃES, Raymundo F. Situaçäo das Finanças do Rio Grande do Sul - 1979-86. Indicadores Fconômicas

FEE, Porto Alegre: FEE, v. 16, n² 2, p. 113-47. set. 1988.

HICKS, John R. Salários e Inflação. In: A Crise na Economia Keynesiana São Paulo: Vértice, 1988.

ROBINSON, Joan. Filosofia Econômica Rio de Janeiro: Zahar. 1979.

ROSS. Arthur M. Órbitas de Comparación Coercitiva In: PIORE, Michael J. (org.) Paro e Inflación: Perspectivas

Institucionales e Estructurales Madrid: Alianza Editorial. 1983.

SCOMAZZON, Valdacyr S. Estatuto do Magistério do Rio Grande do Sul Porto Alegre: Sérgio A. Fabris Editor, 1986.

ZERU HORA. Porto Alegre: 29 set.1991, p. 2

\section{ABSTRACT \\ WHY DO THE BELLS TOLL? LABOR CONFLICT AND THE WAGES OF THE PUBLIC TEACHING CLASS IN RIO GRANDE DO SUL, 1974-1991}

This article analyses the reasons for a labor conflict between the public teaching class and the state government of Rio Grande do Sul. It tries to show that, since 1979, this conflict has been increasing and the reasons may be explained by the public teachers wage deterioration in relative and absolute terms. This situation originated insatisfaction among teachers and created a new trend for strikes, within a greater political freedom environment. It concludes that the maintenance of a wage squeeze policy for the public education system should exacerbate the conflict in the future. 